\title{
Experiência Social e educação popular: diálogos com Edward Thompson.
}

Social experience and popular education: dialogues with Edward Thompson

João Alfredo Costa de Campos Melo Júnior ${ }^{1}$.

\section{RESUMO:}

Coube a este texto retratar o conceito de experiência social desenvolvida pelo historiador britânico Edward Palmer Thompson. Foi na educação de adultos que o conceito de experiência social e popular se solidificou, tornando-se referência para estudiosos que dedicam suas produções à temática.

Palavras-chaves: Edward Thompson, Experiência Social, Educação Popular.

\begin{abstract}
:
It was this text to portray the concept of social experience developed by the British historian Edward Palmer Thompson. It was in adult education that the concept of social and popular experience solidified, becoming a reference for scholars who dedicate their productions to thematic.
\end{abstract}

Key words: Edward Thompson, Social Experience, Popular Education.

Edward Palmer Thompson está inscrito entre os mais frutíferos pensadores do século XX. Na composição de suas pesquisas, além de rigor metodológico, utilizava também uma aguçada curiosidade na composição de suas pesquisas. O conceito de experiência trouxe para Thompson possibilidades analíticas diversas como: culturas populares, associações de trabalhadores, educação de adultos, educação e experiência social, literatura revolucionária, entre tantas outras.

Tendo atuado durante alguns anos como professor de História Social em cursos de educação de adultos, Thompson utilizou como recurso didático primaz, as experiências que seus alunos traziam consigo da concretude de sua realidade de

\footnotetext{
${ }^{1}$ Doutor em Ciências Sociais pela Universidade Federal de São Carlos (UFSCar). Professor Associado II da Universidade Federal de Viçosa - Campus Rio Paranaíba (UFV-CRP).
} 
trabalhadores, utilizando como arcabouço empírico o conjunto de situações cotidianas vivenciadas por seus alunos, ele explica como a relação entre mestre e aprendizes se estabelece:

Toda educação que faz jus a esse nome envolve a relação de mutualidade, uma dialética, e nenhum educador que se preze pensa no material a seu dispor como uma turma de passivos recipientes de educação [...] (THOMPSON, 2002, p. 13).

A relação, quando estabelecida, deveria ser dialogal, em que os participantes envolvidos no processo pudessem interagir em todas as etapas, desde a utilização dos métodos didáticos até a reelaboração dos currículos de ensino. Assim assevera Thompson (2002):

\footnotetext{
O que é diferente acerca do estudante adulto é a experiência que ele traz para a relação. A experiência modifica, às vezes de maneira sutil e às vezes mais radicalmente, todo o processo educacional; influencia os métodos de ensino, a seleção e o aperfeiçoamento dos mestres e o currículo, podendo até mesmo revelar pontos fracos ou omissões nas disciplinas acadêmicas tradicionais e levar à elaboração de novas áreas de estudo (THOMPSON, 2002, p. 13).
}

A premissa inicial levantada pelo autor sugere que, inevitavelmente, há uma aproximação entre os movimentos operários e sociais com o campo das humanidades, fato que possibilitou pesquisas e produções acadêmicas. No entanto, Thompson acrescenta que a História, em particular a História Social, preocupou-se em jogar luz, trazendo para o centro do palco, temáticas ligadas aos movimentos operários e culturas populares e sociais.

São notáveis as possibilidades que se abrem quando o conceito de experiência é colocado na linha de frente; ampliam-se os entendimentos sobre diversos contextos culturais pelos quais a educação nasce e se estabelece ${ }^{2}$. As modificações advindas dos processos educacionais podem ser radicais ou sutis, influenciando fortemente a metodologia empregada pelos professores.

É interesse deste escrito refletir sobre o conceito de experiência traçado pelo historiador britânico. Para tal, como escopo de análise, serão discutidas as experiências educacionais de adultos operários. A relação professor/aluno, construir-se-ia por meio do contato em sala de aula a partir do cotidiano desses educandos. Em grande medida, o

\footnotetext{
${ }^{2}$ Thompson assevera que a historicidade das ações sociais e culturais são fontes de inserção das experiências humanas.
} 
currículo escolar e os métodos de ensino deveriam ser construídos a partir das experiências trazidas pelos alunos.

Com o empreito estabelecido, o texto será dividido em três momentos que, ao cabo, se somarão. Assim, eles serão organizados buscando compreender como se apresentam as experiências culturais, sociais e, por fim, os educacionais.

A cultura, em suas inúmeras formas e performances, constitui um fértil material analítico por meio do qual são construídas experiências que afetam substancialmente os caminhos e processos constituidores da educação popular.

Enquanto interessado pela cultura popular inglesa do século XVIII, Thompson, ao historiar buscou incessantemente jogar luz aos processos de organização dos aspectos culturais nas suas inúmeras concepções formadoras. É nítida a influência de Raymond Williams em seus trabalhos, especialmente, no que concerne à polissemia inerente à área. Williams (1992), assim pensa o termo "cultura ${ }^{3}$."

Tanto o problema quanto o interesse da sociologia da cultura podem ser percebidos de imediato na dificuldade do termo que obviamente a define "cultura". A história e o uso desse termo excepcionalmente complexo [...]. Começando como nome de um processo - cultura (cultivo) de vegetais ou (criação e reprodução) de animais e, por extensão, cultura (cultivo ativo) da mente humana - ele se tornou, em fins do século XVIII, particularmente no alemão e no inglês, um nome para configuração ou generalização do "espírito" que informava o "modo de vida global" de determinado povo. Herder (1784-91) foi o primeiro a empregar o significativo plural, "culturas", para intencionalmente diferenciá-lo de qualquer sentido singular ou, como diríamos hoje, unilinear de "civilização" [...]. (WILLIAMS, 1992, p. 10).

De acordo com Williams (1992), existem diversos nascedouros dos processos culturais que imprimem indelevelmente assinaturas únicas. Esses elementos formativos são, em verdade, características que determinam certas regularidades constituidoras de cultura ${ }^{4}$.

\footnotetext{
${ }^{3}$ Aqui o termo cultura foi colocado entre aspas tal qual retratou Raymond Williams. Para maiores detalhes ver: Williams (1992).

${ }^{4}$ Pensando a multiplicidade do termo cultura, assim escreve Williams: "Respostas alternativas a essas questões têm produzido amplo leque de significados convincentes, tanto dentro da antropologia quanto por extensão, a partir dela: desde a ênfase num espirito formador - ideal, religioso ou nacional - até ênfases mais modernas em uma cultura vivida determinada principalmente por outros processos sociais [...]" (1992, p. 11).
} 
No entanto, Raymond Williams esclarece ainda que dependendo do conteúdo e da área de concentração temática, os caminhos metodológicos de pesquisa levam à seleção de critérios procedimentais que, em alguns casos, opõe-se a uma metodologia tradicional e ortodoxa no campo da sociologia.

É natural que em determinados momentos o campo empírico exija uma convergência teórica como tentativa de absorver a complexidade dos fenômenos culturais. No entanto, em outros momentos, separam-se em circunstâncias diferentes. De um lado, as análises culturais e, de outro, as teorias sociais e historiográficas. Novamente buscando abrigo em Williams (1992):

\begin{abstract}
Antes de nos voltarmos para essa área complexa atual, devemos analisar alguns exemplos importantes de história e análise culturais que não diríamos serem sociológicos, mas nos quais alguns conceitos e métodos fundamentais foram estudados praticamente [...]. Pode-se dizer que obras desse tipo - e há muitos outros exemplos possíveis - têm início de maneira mais evidente a partir da arte e da cultura concreta em questão e, assim podem ser atribuídas à história ou à crítica [...] (WILLIAMS, 1992, p. 20).
\end{abstract}

Thompson compartilhava com seu coetâneo a mesma lógica empírica quando acessava o contexto histórico com objetivo de acessar os conceitos de experiência. Demonstrando interesse na metodologia desenvolvida, apresentou pontos comuns e contrários às percepções de Raymond Williams. Em parte, as divergências assentavamse na construção dos olhares sobre as culturas populares inglesas dos séculos XVIII e XIX. A ênfase da discordância entre Thompson e Williams, assentava-se na compreensão das origens da crise da cultura popular inglesa. Thompson assegurava que para uma melhor compreensão da crise era imprescindível que o pesquisador recuasse temporalmente para entender as causas da crise no romantismo dos fins do século XVIII. Já para Williams, o recuo temporal não se fazia necessário, uma vez que a interligação entre cultura popular e vida social já estavam postas.

O pressuposto levantado pelo historiador britânico sobre a cultura inglesa do século XVIII, apoiava-se na compreensão de que os processos culturais ingleses se constituíram a partir de estruturas paternalistas. Em outros termos, a proposição thompsoniana declarava com segurança que existia uma substancial diferença entre a experiência cultural erudita e a popular. A chave era o paternalismo oriundo da classe educada (Thompson, 2002). 
Continuando sua explicação, Edward Thompson, revela aos seus leitores que no século XVIII inglês a cultura de um homem servia como demarcador de posição social. Tal fato não corrobora a ideia da existência de uma segregação cultural e social entre as classes envolvidas, pelo contrário. A citação revela a compreensão alargada de Thompson em relação à luta de classes:

Isto não significa que a aristocracia ignorasse ou desprezasse a cultura do povo. Pelo contrário, muitos de seus representantes eram tolerantes e curiosos. Alguns ajudavam ativamente os divertimentos populares: levantavam os fundos para as lutas com prêmios em dinheiro, arranjavam uma briga de galos com os fazendeiros vizinhos ou até mesmo presidiam as disputas esportivas no gramado da aldeia [...] (THOMPSON, 2002, p. 17).

Há aqui um alargamento do conceito de luta de classe ao imputar sobre ele novas camadas que contrastavam com uma interpretação mais monolítica que pensava esse fenômeno histórico tão somente como o antagonismo entre classes sociais, fato que geraria o movimento teleológico da história humana ${ }^{5}$. Não há dúvidas de que Thompson partiu do conceito de luta de classe, no entanto, com o lançamento do clássico $A$ Formação da Classe Operária Inglesa (1963), em função de sua perspectiva teórica, outros fatores, para além dos marcadores estruturais, foram adicionados às análises teóricas e empíricas. Dentre eles pode-se mencionar a utilização de ações culturais em suas mais variadas facetas, como por exemplo, literaturas "ditas marginais", teatro popular, festejos, esportes de luta, rinhas de animais e tantas outras manifestações vindas das classes pobres.

Desde sua concepção original, o escopo da obra era refletir sobre a formação de processos de ação coletiva, associados a elementos da cultura popular e literária como forma de resistência aos efeitos danosos da revolução industrial nas baixas camadas populares da Inglaterra naquele momento histórico.

A Formação da Classe Operária Inglesa é o retrato fidelizado do movimento interno da consciência de classe daqueles atores sociais que carregam consigo as vozes e os corpos, até então esquecidos pela dita historiografia oficial. O resultado imediatamente visível é a vivacidade luminosa que Thompson imprime à condição operária, isto é, em seu livro, o historiador britânico leva homens e mulheres a

\footnotetext{
${ }^{5}$ O Objetivo deste artigo é trabalhar os conceitos de Experiência Social e Culturas populares nos trabalhos de E.P. Thompson. Cabe esclarecer que este texto não levantará o clássico debate sobre a luta de classe no modo de produção do capitalismo e seus reflexos nos níveis ideológicos.
} 
romperem com sua condição social. Devolvia dignamente para trabalhadores e trabalhadoras a capacidade de enfrentar as dificuldades através da liberdade de agir, subverter e romper com as barreiras intelectuais que os colocavam afixados em suas estruturas sociais originárias.

As ações coletivas empreendidas trazem na lógica thompsoniana, a organização empreendedora da classe operária, agindo racionalmente por meio de suas experiências sociais e culturais no princípio das lutas de classe. Há, portanto, uma inversão do componente teleológico do marxismo tradicional ${ }^{6}$.

O deslocamento teórico vislumbrado por Edward Palmer Thompson trouxe à superfície a capacidade, até então, quase esquecida, por parte da historiografia marxista de auto-organização das classes trabalhadoras e populares. No epicentro de suas análises, estão experiências reais e concretas de operários e operárias. Outrossim, não houve por parte de Thompson um abandono ou completo desprezo, como queriam crer, determinadas correntes do marxismo estruturalista ${ }^{7}$, das relações de exploração no interior do sistema. Em seus trabalhos, ao contrário da pressuposição estruturalista, o historiador acenava sobre a exploração classista, todavia inserida em um contexto histórico maior: de luta e consciência de classe. As classes sociais são, para Thompson, originárias de processos externos; entre eles o teatro popular, o pugilismo, a literatura e tantos outros. Não existe um padrão teórico estabelecido que consiga dimensionar classe social no seu tipo/modelo mais puro e intocado, tamanha sua volatilidade.

Trazendo novamente para o centro da análise o paternalismo, nota-se que esse tema alarga sensivelmente o entendimento sobre as relações entre as classes. Portanto, a convicção do autor demonstra que a força estruturante do paternalismo barrava alguns elementos da cultura popular, mas, por outro lado, compreendia e assimilava outros tantos. O exemplo levantado pelo autor centra-se nas canções populares e seus diversos dialetos (Thompson, 2002). Os exemplos trazidos à superfície são notórios ao traçar com profundidade reveladora e até mesmo tocante.

\footnotetext{
${ }^{6}$ A concepção teleológica de origem hegeliana, pensava o movimento histórico e suas realidades particulares, para uma finalidade última.

7 Dentre as críticas impetradas a Thompson a mais severa questionava que ele abandonara propositalmente em suas pesquisas as relações de exploração em detrimento de um culturalismo exacerbado e pouco crítico.
} 
A sagacidade de Thompson revela-se em suas análises. Buscando abrigo em Werther, personagem de Goethe, Thompson (2002), em um trecho de seu ensaio "Educação e Experiência", exemplifica com assustadora clareza as diferentes camadas que existem nas relações estruturantes entre as classes letradas e iletradas. Ao trazer para a ribalta as relações do jovem apaixonado por Charlotte com a classe pobre, o autor, com sucesso, revelou, por meio do romance, as aproximações, assimilações e diferenças entre as classes, interpretando as ações de Werther, quando presenciou o infortúnio de uma relação que chegava a seu fim. Com um profundo espanto, constata que a rude classe popular também nutria sentimentos de dor, perda e desalento, que também são componentes do amor romântico ${ }^{8}$ Ao buscar socorro em um clássico da humanidade, Edward Thompson procurou ampliar a percepção sobre as relações entre as classes letradas e iletradas. Talvez a intenção fundamental pretendida pelo historiador fosse revelar em vivas tonalidades que havia, de certo modo, aproximações entre as noções de cultura e, que, em grande medida, acontecia por meio dos esforços marcados pela curiosidade da classe senhoril.

A estratégia de leitura traçada é entender Werther como voyeur da vida dos pobres (Thompson, 2002, p 21.). A impressão revelada pelo historiador britânico é que a personagem central do romance de Goethe se excitava com o cotidiano das camadas populares. A argumentação se construiu da seguinte forma:

Mas, mesmo se o caminho é direto, já há uma certa mudança: um divisor de águas foi cruzado. Não tanto pelo que é dito, mas a intensidade com que é sentido. Suspeita-se que Werther é um vouyeur da vida dos pobres, que usa para se excitar [...] (THOMPSON, 2002, p.21).

Ao utilizar Os Sofrimentos do Jovem Werther, Thompson pretendeu robustecer o conceito de paternalismo que prevalecia nas relações entre as classes envolvidas em seus processos constituidores. A ampliação do entendimento, com a aquisição do conceito, revelou a preocupação cada vez mais crescente da aristocracia com o bemestar dos pobres 9 .

\footnotetext{
${ }^{8}$ Werther impressiona-se com a tristeza humanizadora de um pobre camponês que demonstrava a perda de sua esposa através de um sofrimento agudo e dilacerante. Tal sentimento comoveu quase às lágrimas o impressionado herói romântico e apaixonado.

${ }^{9} \mathrm{O}$ argumento de Thompson reforça a tese de uma relação de proximidade entre a aristocracia e os pobres, no que tange à convivência entre elas. Afirma o autor: "houve um aumento da preocupação por parte da aristocracia em relação aos pobres: as escolas dominicais e sociedades que lutam pela melhoria
} 
No entanto, a situação entre as duas classes se modifica transformando, com isso, o entendimento sobre o paternalismo. Há um corte radical e profundo nas possibilidades de intervenções dos grupos aristocráticos sobre as classes pobres. A partir de então, os populares teriam liberdade de agir, trabalhar e até mesmo divertiremse como melhor lhes aprouvessem ${ }^{10}$.

Mesmo ampliando a condição de divertimento das classes populares, elas deveriam ser autorizadas e acima de tudo, organizadas para que nada saísse do controle das elites. Pode-se intuir que o que existia era uma vontade de vigiar as atitudes e os desejos do povo pobre. O entendimento de Edward Thompson (2002) é ainda mais arguto e incisivo, de acordo com ele:

O desejo de dominar e de moldar o desenvolvimento intelectual e cultural do povo na direção de objetivos predeterminados e seguros permanece extremamente forte durante a época vitoriana: e continua vivo ainda hoje (THOMPSON, 2002, p. 31).

Em fins do século XVIII, iniciou-se um movimento nas sociedades de ajuda mútua e desenvolvimento que buscava instruir as classes populares por meio de cursos, palestras, aulas, leituras coletivas de peças e livros. A educação começava, portanto, a movimentar aquele cenário, transfigurando rapidamente as condições culturais e intelectuais das camadas populares. As consequências expostas à vista são aquelas percebidas nas fissuras da cultura popular, em particular na compreensão das experiências.

A educação erudita, como bem lembra Thompson (2002), penetrou no cotidiano das classes populares como um tornado, modificando radicalmente o modo de agir e se portar frente às possibilidades e demandas culturais e educacionais. As vivências tradicionais foram desestimuladas e acima de tudo, tratadas e lidas como abjetas e imorais. A consequência visível foi a quebra das experiências adquiridas ao longo do percurso.

das condições de vida e pela supressão dos vícios dos pobres recebem alguma atenção" (THOMPSON, 2002, p. 26).

${ }^{10}$ Em ocasião de uma palestra realizada em Leeds, universidade onde autor exerceu a função de professor de História Social na educação de adultos nos anos de 1950, no ano de 1968, intitulada "Educação e Experiência", Edward Thompson elabora o conceito de paternalismo a partir de duas chaves: uma primeira oriunda de uma onda contrarrevolucionaria que obstruía as classes populares justificada pelo receio do surgimento de movimentos revolucionários. Já o segundo momento buscou, dentro dos limites da legislação, possibilitar certa autonomia aos empregados. 
O autodidatismo, um dos cenários pujantes e demarcadores da condição de sobrevivência da classe pobre, foi sendo quebrado pelas ações educacionais por parte da classe letrada. A rejeição ao conhecimento natural apoiava-se na convicção de que ele era grosseiro, imoral e ignorante. A compreensão thompsoniana sobre o tema caminhava para revelar que a aceitação ocorria de modo passivo e sem fricção por meio de um adestramento educacional. As impressões de Thompson foram construídas da seguinte forma:

Não é difícil compreender e aceitar as pressões dos homens nessa situação. A realização dos objetivos do movimento da classe trabalhadora exigia - não apenas de seus líderes, mas também de milhares de seus membros comuns novos atributos da autodisciplina, do auto respeito e treinamento educacional [...] (THOMPSON, 2002, p.32).

A inserção desses "novos atributos", como relatou o historiador britânico, promoveu um corte radical e profundo na organização das ações empreendidas pelos trabalhadores. Demandas consideradas históricas, pouco a pouco foram abandonadas ou desestimuladas pelas ações cotidianas que visavam, acima de tudo, rejeitar as conquistas intelectuais, culturais e sociais advindas das experiências populares. Thompson (2002) analiticamente percebeu que uma minoria lutava de modo quase incessante pela preservação dos costumes e das tradições originárias. Tarefa hercúlea e inglória, na medida em que as desistências se avolumavam ao longo do tenso percurso. O exemplo trazido é marcante, diz ele:

Depois de mais de quarenta anos de destacado serviço, esse excepcional líder
dos sindicalistas londrino, John Gast, explodiu de repente para Francis Place,
em 1834: "O único caminho para o Cérebro de um inglês é através de sua
barriga". "Eu próprio, continuava ele, "pertenço a uma instituição da cidade
que dá palestras todas as noites de domingo, e algumas vezes durante a
semana, e temos tido uma boa frequência, todos nós somos trabalhadores na
palestra". Mas, ao mesmo tempo, lamenta a ignorância e o alcoolismo da
"parte vulgar e ignorante do povo" [...] (THOMPSON, 2002, p. 33)

A intenção subjacente do ególatra Francis Place era a formatação do caráter e do corpo dos trabalhadores pobres, por meio de palestras dominicais e outras atividades 
correlatas. E.P. Thompson (2002), argumenta que o desejo de Place sempre foi o mesmo: dominar e moldar aqueles que frequentavam aquele ambiente ${ }^{11}$. A pressão "disfarçada" avolumou-se com o passar dos anos.

O marco temporal, grosso modo, do arrefecimento cultural sobre a classe pobre aconteceu em fins do século XVIII. A denominada "marcha do intelecto", pelas sociedades de ajuda mútua, que realizavam palestras dominicais que visavam superar, dinamitando, as tradicionais experiências cotidianas dos trabalhadores braçais.

Do mesmo modo, Thompson levanta o argumento que a integração entre as culturas erudita e popular não ocorreu de modo espontâneo. Admiravelmente houve a necessidade de conservação de alguns costumes e, de outra maneira, a superação de experiências culturais. Talvez, o exemplo maior fosse das canções folclóricas, que eram revividas e algumas esquecidas no profundo limbo da memória histórica. O alerta é retumbante: determinados trabalhos acadêmicos, evoca Thompson, evidenciam propositalmente apenas os aspectos negativos que colocavam no pódio a incivilidade das classes populares ${ }^{12}$.

A contrapartida era premente, e foi feita ao alertar que, de modo proposital, deixaram-se de lado as manifestações culturais positivas, tais como o fardo das colheitas, os dialetos, os festivais que comemoravam o fim do período das colheitas, entre outras.

A educação erudita, de acordo com a tese de Thompson, mais do que a bússola que apontava novos caminhos para classe iletrada, foi também o impulso para a desagregação de uma matriz cultural originária. A longa citação parece bastante sintomática:

a educação se apresentava não apenas como uma baliza na direção de um universo mental novo e mais amplo, mas também como uma baliza para longe, para fora, do universo da experiência no qual se funda a sensibilidade. Além do mais, na maior parte das áreas durante o século XIX, o universo instruído estava um desprezo vigorosos da linguagem, costumes e tradições da cultura popular tradicional. $\mathrm{O}$ homem trabalhador autodidata, que

\footnotetext{
${ }^{11}$ De olhar agudo sobre as culturas populares, Thompson constrói a seguinte análise: “O desejo de dominar e de moldar o desenvolvimento intelectual e cultural do povo na direção de objetivos predeterminados e seguros permanece extremamente forte durante a época vitoriana: e continua vivo e ainda hoje (THOMPSON, 2002, p. 31).

12 Thompson argumentava que determinadas pesquisas traziam apenas situações culturais de grande rudeza, como, por exemplo, pugilismo criminoso, rinha de animais, entre outras aviltantes situações.
} 
dedicava suas noites e seus domingos à busca do conhecimento, era também solicitado, a toda hora, a rejeitar todo o cabedal humano de sua infância e de seus companheiros trabalhadores como grosseiro, imoral e ignorante. (THOMPSON, 2002, p. 32).

A estratégia de desmobilização da cultura popular, passou necessariamente pelo processo educacional que buscava suprimir os possíveis resquícios que se amalgamavam na memória mais profunda das crianças e dos jovens. Portanto, a função do professor seria, de acordo com o autor, desestimular possíveis cenários de rebeldias populares. O pavor de uma insurreição popular levou ao arrefecimento de uma educação que restringia as experiências populares como matéria constituidora de saber.

Havia um claro processo de ruptura entre a educação e as experiências sociais herdadas. Os polos se distanciavam peremptoriamente sob a rígida batuta de professores e mestres que construíam didáticas que jogavam para escanteio todas e quaisquer manifestações culturais que se validavam pelas experiências populares.

O abismo entre a educação chamada erudita e as consciências populares tornouse, então, intransponível. Dois mundos irreconciliáveis que se tencionavam. Nesse cenário, revela Thompson (2002), os trabalhadores foram os que receberam o pesado impacto. É desta maneira que é descrito:

E os trabalhadores que, por seus próprios esforços, conseguiam penetrar na cultura letrada viam-se imediatamente no mesmo lugar de tensão, onde a educação trazia consigo o perigo da rejeição por parte de seus camaradas e a autodesconfiança. Essa tensão ainda permanece (THOMPSON, 2002, p.36).

A oposição entre as culturas letradas e populares intensificou-se a partir da conjunção de fatores religiosos e educacionais, que marcaram, a ferro quente, as experiências das classes subalternas. A leitura feita pelo historiador inglês passava pelo entendimento de que educadores britânicos não diferenciavam a função educacional do controle social. O resultado visível foi a severa oposição entre essas duas realidades.

Ao que parece, a segregação pela educação criou raízes profundas que solidificaram ainda mais as diferenças existentes entre o mundo erudito e o mundo das experiências populares. A afetação, segundo Edward Thompson acontecia a partir de uma lógica reversa. Os trabalhadores que, por esforço e méritos, conseguiram avançar culturalmente sofreram apontamentos e admoestações oriundos de seu lócus originário. 
Sem dúvida alguma, a rejeição foi um pesado fantasma que assombrava atrás da porta aqueles que teimavam em buscar qualificações culturais.

Mesmo com todas as adversidades colocadas às claras, o impulso pela educação ainda se mantinha vivo e pulsante nas intenções de alguns membros das camadas populares $^{13}$. Há aqui o estabelecimento de uma clara relação dialética entre as experiências populares e a cultura letrada, argumenta o autor ${ }^{14}$.

A observação dialética sobre as classes possibilitou o entendimento de que as culturas letrada e iletrada não são ilhas isoladas e incomunicáveis, pelo contrário. Thompson (2002) sustentou que se comunicavam, interagiam, modificavam-se e estruturavam-se. Noutro extremo, surge um alerta: se há alguma forma de segregação é auto intencional, é marcada no trecho:

A cultura letrada não está isolada em relação à cultura do povo à maneira antiga de diferença de classes, mas, não obstante, está isolada dentro de suas próprias paredes de auto estima intelectual e de orgulho espiritual (THOMPSON, 2002, p. 43).

Soa farsesca a infecunda tentativa de isolamento perpetrada pela cultura letrada com relação às expressões culturais advindas de ações sociais ligadas às camadas populares. Esse é o alerta que os professores deveriam repassar a seus alunos nas universidades. Ao professor universitário, de acordo com Thompson, caberia agir como um semeador intelectual. A tarefa consistiria também em uma criteriosa seleção do material utilizado em sala, a busca por bibliografias pertinentes à proposição temática, sem esquecer a capacitação profissional.

O tom impresso nas análises de Thompson mostrou que a democratização do conhecimento originaria prioritariamente das universidades, que deveriam ser espaços abertos e receptivos às experiências sociais e às culturas populares.

\footnotetext{
${ }^{13} \mathrm{O}$ argumento de Thompson é construído no sentido de revelar que o impulso à educação ocorria em diferentes lugares ao longo do século XIX. Entretanto, a falha acontecia no entendimento de que educação e experiência eram forças opostas. Diz ele: "O impulso permanece, é claro; pode-se vê-lo em uma centena de lugares no século XIX. Talvez sua fraqueza resida na tendência a considerar o conflito entre educação e experiência como sendo entre o intelecto (ou mero intelecto mecânico) e o sentimento; e, em desespero, superestimar este último em relação ao primeiro (THOMPSON, 2002, p.36).

${ }^{14}$ Neste sentido Thompson deixa bastante explícito que as relações estabelecidas como ação contínua entre a educação formal e as experiências populares e trabalhistas aconteciam de modo dialético. A leitura thompsoniana sobre as culturas populares inglesas reclamava abrigo metodológico na percepção dialética.
} 
As universidades deveriam tornar-se espaços, por excelência, abertos, democráticos e receptivos às circularidades culturais advindas de experiências multifacetadas de classes populares. De outro lado, quando não observado, o resultado seria o contrário:

[...] o perigo é que esse tipo de tecnologia profissional necessária seja confundida com autoridade intelectual e que as universidades apresentando-se como um sindicato de todos os "peritos" em cada ramo do conhecimento - expropriem pessoas de sua identidade intelectual [...] (THOMPSON, 2002, p. 43).

A denúncia dos malefícios causados pelo fechamento dos portões universitários para a circularidade das culturas poderia gerar a segregação de espaços que, em verdade, soavam como complementares. A erradicação do problema estaria dentro das próprias instituições superiores de ensino que, por meio do então denominado “departamento extramuros", ${ }^{15}$ avançava na relação entre "esses dois mundos" que coexistiam separados.

As conexões entre os saberes erudito e as experiências originadas das culturas populares reverberavam em ganhos de potência tanto no interior das universidades como nas camadas populares. A base de sustentação da relação é a capacidade de interação entre as partes envolvidas. Mesmo levando em consideração a volatilidade e a constante alternância do público, as relações entre os dois saberes precisa continuar intacta e pulsante. A recomendação fundava-se no receio de uma exacerbada, e muitas vezes, improdutiva profissionalização.

No entendimento de Thompson (2002), a exacerbação da profissionalização causaria impactos negativos na construção da dialética entre o erudito e o popular, uma vez que, inevitavelmente ocorreria o isolamento intramuros da universidade. Todavia, adverte o autor que o departamento não deveria abrir-se à tentação de alcançar um público avolumado para que não se perdessem os fatores essenciais da relação então estabelecida.

\footnotetext{
${ }^{15} \mathrm{O}$ departamento extramuros das universidades, equivaleria, sobretudo, aos Departamentos de Educação de Adultos, atualmente denominadas Departamento de Educação Continuada.
} 
A construção do projeto pedagógico voltado para a educação de adultos sustentava-se na reciprocidade entre os atores envolvidos durante os períodos de aulas e cursos livres. Conclui Thompson (2002):

\begin{abstract}
Não há correlação automática entre o "sentimento real e a razão justa" e as conquistas educacionais, mas as pressões de nossa época estão nos levando a confundir duas coisas - e os professores universitários, que nem sempre se destacam por sua humildade, estão frequentemente prontos a concordar com essa confusão. É sempre difícil conseguir o equilíbrio entre o rigor intelectual e o respeito pela experiência, mas hoje em dia este equilíbrio está seriamente prejudicado. Se eu tiver corrigido esse desequilíbrio um pouco, fazendo-nos lembrar que as universidades se engajam na educação de adultos não apenas para ensinar mas também para aprender, terei então conseguido meu objetivo (THOMPSON, 2002, p. 46).
\end{abstract}

Edward Palmer Thompson dedicou-se à docência de adultos em programas universitários voltados para esse tipo de público, fato que o possibilitou criar estratégias educacionais e pedagógicas que facilitaram a relação ensino-aprendizagem. A chave para o aperfeiçoamento e a aproximação dos estudantes, sempre esteve no cotidiano dos trabalhadores que frequentavam as aulas do professor Edward.

As experiências trazidas pelos alunos serviram como um poderoso fermento para suas aulas ministradas. E Thompson, habilmente, utilizou as vivências profissionais, culturais e pessoais de seus alunos para montar o padrão de aula. $\mathrm{O}$ estratagema surtiu efeito multiplicador no ensino de adultos. A metodologia empregada que associava experiências e culturas populares como base da educação de adultos ultrapassou as barreiras universitárias, alçando Edward Palmer Thompson ao posto de um dos mais importantes historiadores e críticos sociais do século $\mathrm{XX}^{16}$.

Coube a este trabalho refletir sobre os conceitos de experiência social, culturas populares e educação a partir dos pressupostos teóricos e metodológicos de E.P. Thompson. Como um dos mais importantes e respeitados pesquisadores das culturas populares e operárias dos séculos XVIII e XIX, legou a seus leitores importantes obras referenciais que permitem diversas leituras e entendimentos. As pistas e referências foram dadas pelo historiador inglês. Basta-nos segui-las.

\footnotetext{
${ }^{16}$ Em 1968, em função da conferência anual do Albert Mansbridge Memorial, Thompson realizou a palestra intitulada "Educação e Experiência", através da qual expôs o conceito de experiência nas humanidades e desenvolveu outras reflexões.
} 


\section{REFERÊNCIAS:}

ADORNO, Theodor. Educação e Emancipação. Rio de Janeiro: Paz e Terra, 1995.

CANCLINI, Néstor G. A Sociedade Sem Relato. Antropologia e Estética da Iminência. São Paulo: Edusp, 2016.

EAGLETON, Terry. A Ideia de cultura. São Paulo: Editora da Unesp, 2005.

GOETHE, Johan Wolfgang. Os Sofrimentos do Jovem Werther. São Paulo: Martin Claret, 2004.

GUMBRECHT. Hans Ulrich. Nosso Amplo Presente. O tempo e a cultura contemporânea. São Paulo: Editora da Unesp, 2015.

HOBSBAWM Eric, TERENCE Ranger. A Invenção das Tradições. Rio de Janeiro: Paz e Terra, 1997.

MELO JÚNIOR, João Alfredo Costa de Campos. A noção de Experiência Histórica e Social em Edward Thompson: percursos iniciais. História e Perspectivas - Revista dos Cursos de Graduação e do Programa de Pós-graduação em História. Número 1- Edição Especial, pp 393-413. Uberlândia: Editora da UFU, 2014.

MELO JÚNIOR, João Alfredo Costa de Campos. Fronteiras de um mesmo diálogo: Edward Thompson, Charles Tilly e as possibilidades da pesquisa em História da Educação. In: Nas obras de Clio: História Social e História da Educação. Belo Horizonte: Mazza Edições, 2014.

MELO JÚNIOR. João Alfredo Costa de Campos. Edward Palmer Thompson (19241993). In: Os Historiadores. Clássicos da História. Vol 2. De Tocqueville a Thompson. Petrópolis: Vozes, 2013.

THOMPSON, Edward Palmer. Educação e Experiência In: Os Românticos. A Inglaterra na era Revolucionária. Rio de Janeiro: Civilização Brasileira, 2002. P. 1147.

THOMPSON, Edward Palmer. As Peculiaridades dos Ingleses e Outros Artigos. Campinas: Editora da Unicamp, 2001.

THOMPSON, Edward Palmer. A Formação da Classe Operária Inglesa (3 volumes). Rio de Janeiro: Paz e Terra, 1987 [1963]. 
THOMPSON, Edward Palmer. Senhores e caçadores. Rio de Janeiro: Paz e Terra, 1987. WILLIAMS, Raymond. Cultura. Rio de Janeiro: Paz e Terra, 1992. 